\title{
Craniofacial morphology in overweight and obese orthodontic adolescent patients
}

\author{
Katarzyna Olszewska' \\ ${ }^{1}$ Chair and Department of Paedodontics, Medical University in Lublin, Poland \\ Olszewska K. Craniofacial morphology in overweight and obese orthodontic adolescent patients. J Pre-Clin Clin Res. 2017; 11(1): 42-45. doi: \\ 10.26444/jpccr/75138
}

\begin{abstract}
Introduction and objective. There is an evidence suggesting that obesity may influence the timing of puberty and growth patterns. There are few research on the reactions of the craniofacial complex to an overall increase in the body mass. Thus the objective of the study was to investigate if overweight or obesity may influence craniofacial morphology in adolescent orthodontic patients.

Material and methods. In total, 77 patients aged 11-16 years were selected for the retrospective analysis. The study group comprised 37 overweight or obese individuals (mean age: 13,45 $\pm 2,15$ ). The control group included 40 normal-weight subjects (mean age: 13.79 \pm 1.81 ). Body mass index (BMI) percentile of each patient was assessed with the use of BMI score and age- and sex specific growth charts in accordance with International Obesity Task Force (IOTF). Craniofacial measurements included in the study were performed on the tracings of lateral cephalometric radiographs. The data was analyzed by STATISTICA 10 for Windows Software.

Results. Both females and males of the study group exhibited significantly greater mandible length (Cd-Gn), corpus length (Go-Pg), midfacial length (Cd-A) and lower anterior facial height (Ans-Me) $(\mathrm{p}<0.05)$, as well as SNB, SNPg and ML/SN angles $(p<0.05)$ compared to the normal-weight controls. Moreover, high BMI females showed greater maxillary length (Pm-A) and SNA angle $(p<0.05)$, whereas males exhibited greater posterior facial height $(S-G o)(p<0.05)$ compared to the controls. Conclusions. Weight status is an important factor that can affect craniofacial growth pattern and should be taken into consideration when planning orthopaedic treatment in adolescent patients.
\end{abstract}

\section{Key words}

overweight, obesity, adolescents, craniofacial growth, cephalometrics

\section{INTRODUCTION}

Obesity is one of the major global health challenges of the 21st century. Its prevalence has nearly doubled since 1980 and is still increasing at an alarming rate [1]. According to the World Health Organization, globally 170 million children (aged $<18$ years) are estimated to be overweight and in some countries the number of overweight children has trebled since 1980 [2]. The vast majority of overweight or obese children live in developing countries, where the rate of increase has been more than $30 \%$ higher than that of developed countries [3]. $23.8 \%$ of boys and $22.6 \%$ of girls from developed countries were overweight or obese in 2013 worldwide [1]. In Europe, the highest rates of childhood obesity are noted in the Eastern and Mediterranean countries [3]. In Poland, between 19712000 , the incidence of overweight and obesity in children from Cracow doubled from $7.5 \%$ to $15.2 \%$ in boys and from $6.5 \%$ to $11.8 \%$ in girls. The results obtained in 2009 revealed a further increase in the percentage of overweight and obese children, reaching $35 \%$ in boys and almost $20 \%$ in girls [4]. In 2008 in south-eastern Poland, the prevalence of overweight was $13.3 \%$ in girls and $14.2 \%$ in boys, whereas the prevalence of obesity was $7.7 \%$ in girls and $6.4 \%$ in boys [5].

According to Centers for Disease Control and Prevention, for children and adolescents (aged 2-19 years), overweight is defined as a BMI at or above the 85th percentile and lower than the 95th percentile for children of the same age and gender, whereas obesity is defined as a BMI at or above the 95th percentile $[6,7]$.

Address for correspondence: Katarzyna Olszewska, Chair and Department of Paedodontics, Medical University in Lublin, Poland

E-mail: olszewskakm@interia.pl

Received: 11 Novembere 2016; accepted: 23 January 2017
Nutrition is an important regulator of the tempo of human growth and prepubertal high BMI percentile is usually associated with an early onset of puberty, precocious skeletal maturation and accelerated dental development [8-16].

There is aLSO evidence suggesting that obesity may influence the timing of puberty and growth patterns. Obese girls and boys present an earlier onset of puberty and completion of puberty with a shorter duration of puberty compared to the normal-weight peers. They tend to be taller during pre-puberty but lose this growth advantage during puberty and have a similar adult height compared to normalweight children [17].

Leptin, discovered in 1994 by Zhang et al., is a candidate for a hormone that might have a regulatory function for body fat levels [18]. Leptin is secreted by adipocytes and regulates appetite and metabolism via hypothalamic mediators. Leptin accelerates the production of a gonadotropin-releasing hormone by the hypothalamus, and was shown to slowly rise before puberty, and might play a permissive role for the onset of puberty. Leptin was also shown to be important in the development of the skeleton and may impact craniofacial growth. Moreover, it has been hypothesized that it acts directly at the level of skeletal growth centrrs by inducing chondrocyte differentiation and proliferation [19].

Craniofacial growth is a complex interaction between genes and hormones. The effects of an altered body growth on craniofacial structures have been studied in children and adolescents with reduced somatic growth of different causes $[20,21]$. In the literature, there is little research on the reactions of the craniofacial complex to an overall increase in the body mass $[23,24,25]$. Thus, the objective of the study was to investigate whether overweight or obesity may influence craniofacial morphology in adolescent orthodontic patients. 


\section{MATERIALS AND METHOD}

A retrospective analysis of pretreatment medical records of the patients of two orthodontic clinics was performed. From a total number of analysed patients, 77 were selected for the study. The study group enrolled 37 individuals with high BMI percentile (22 females, 15 males, mean age: $13.45 \pm 2.15$ ), including 24 overweight patients (BMI equal or greater then $85^{\text {th }}$ percentile but lower than $95^{\text {th }}$ percentile) and 13 obese patients (BMI equal or greater than $95^{\text {th }}$ percentile). The control group included 40 normal-weight individuals (24 females, 16 males, mean age: $13.79 \pm 1.81$ ).

The inclusion criteria for both groups were: age ranging between 11-16 at the time of the pretreatment record, BMI equal or greater than $85^{\text {th }}$ percentile, lateral cephalometric radiograph of a good quality, weight and height recorded within one month of the lateral cephalometric radiograph, no history of systemic diseases or therapy that may impact on the growth and development process. Patients with severe skeletal defects in the anteroposterior or vertical dimension were excluded from the study.

Body mass index (BMI) percentile of each patient was assessed with the use of BMI score and age- and genderspecific growth charts. The BMI score was defined as the body mass divided by the square of the body height and was universally expressed in units of $\mathrm{kg} / \mathrm{m}^{2}$. The data concerning body mass and body weight of the patients was taken from the pretreatment medical records, as taking these measurements is a routine procedure in the orthodontic pretreatment examination. Patients were classified into normal-weight, over-weight or obese in accordance with the criteria proposed by International Obesity Task Force (IOTF) [7].

Craniofacial measurements included in the study were performed on the tracings of lateral cephalometric radiographs. Radiographs were taken according to a standard method, with the right side of the patient's face oriented towards the X-ray tube and with the teeth in habitual occlusion. Figure 1 shows the cephalometric reference points and lines used for angular and linear measurements. The following angular measurements: SNA, SNB, SNPg, ANB, NL/SNL, ML/SN, ML/NL, and linear measurements: mandibular length (Cd-Gn), corpus length(Go-Pg), midfacial length (Cd-A), maxillary length (Pm-A), cranial base length $(\mathrm{S}-\mathrm{N})$, posterior facial height (S-Go), anterior facial height (N-Me), lower anterior facial height (Ans-Me) were assessed in the study.

Statistical analysis. The data was analyzed by STATISTICA 10 for Windows Software (StatSoft Inc., Tulsa, USA). All data were reported using descriptive statistics like mean and standard deviation (SD). The normality of the distribution of variables was tested using Shapiro-Wilk test. Differences in continuous variables between the study group and the control group were assessed by unpaired $t$-test. P value $<$ 0.05 was considered statistically significant.

\section{RESULTS}

As shown in Tables 1 and 2, several angular and linear craniofacial measurements were significantly greater in the study group, both in females and males, in comparison with the normal-weight controls.

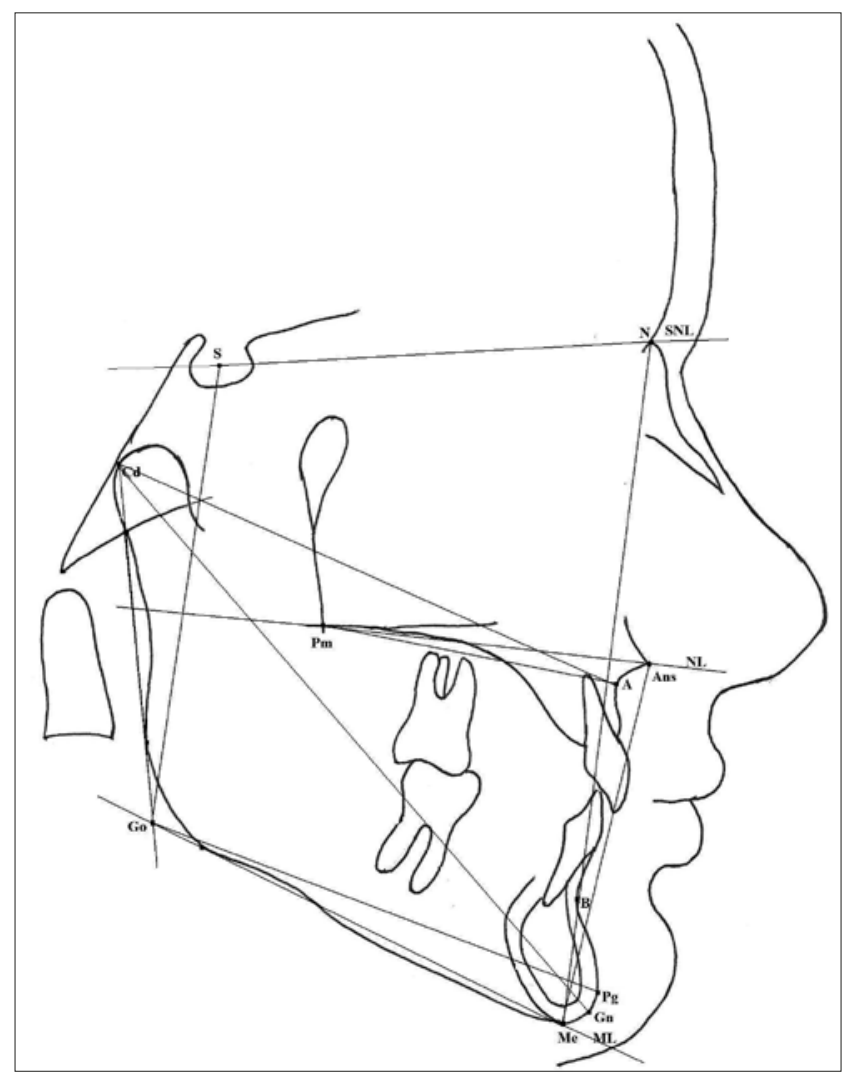

Figure 1. Cephalometric points and lines used in the analysis.

A: subspinale, Ans: anterior nasal spine, Ar: articulare, B: supramentale, Ba: basion, $\mathrm{Cd}$ : condylion, Gn: gnathion, Go: gonion, Me: menton, N: nasion, Pg: pogonion, Pm: pterygomaxillare, S: sella, SNL: sella-nasion line, NL: nasal line, ML: mandibular line, Cd-Gn: mandibular length, Go-Pg: corpus length, Cd-A: midfacial length, PmA: maxillary length, $\mathrm{S}-\mathrm{N}$ : cranial base length, $\mathrm{S}-\mathrm{Go}$ : posterior facial height, $\mathrm{N}-\mathrm{Me}$ : anterior facial height, Ans-Me: lower anterior facial height

Table 1. Craniofacial measurements in females of the study and control groups

\begin{tabular}{|c|c|c|c|c|c|c|}
\hline & \multicolumn{2}{|c|}{ Study group $n=37$} & \multicolumn{2}{|c|}{ Control group $n=40$} & \multirow[b]{2}{*}{$\mathrm{t}$} & \multirow[b]{2}{*}{$\mathrm{p}$} \\
\hline & Mean & SD & Mean & SD & & \\
\hline Age & 13.75 & 2.36 & 13.96 & 2.85 & 6.2736 & $0.0000^{*}$ \\
\hline \multicolumn{7}{|c|}{ Linear measurments $(\mathrm{mm})$ : } \\
\hline Cd-Gn & 115.73 & 2.12 & 110.33 & 2.51 & 7.8295 & $0.0000^{*}$ \\
\hline Go-Pg & 73.00 & 2.29 & 70.33 & 2.14 & 4.0839 & $0.0002^{*}$ \\
\hline $\mathrm{Cd}-\mathrm{A}$ & 90.32 & 1.98 & 84.96 & 2.18 & 8.699 & $0.0000^{*}$ \\
\hline Pm-A & 46.68 & 1.73 & 44.71 & 1.61 & 4.0197 & $0.0002^{*}$ \\
\hline S-N & 70.04 & 2.34 & 70.79 & 2.98 & -0.939 & 0.3528 \\
\hline S-Go & 73.14 & 2.61 & 72.42 & 2.04 & 1.0474 & 0.3006 \\
\hline $\mathrm{N}-\mathrm{Me}$ & 110.23 & 1.79 & 110.25 & 3.01 & -0.0307 & 0.9756 \\
\hline Ans-Me & 65.27 & 1.95 & 62.45 & 2.83 & 3.890 & $0.0003^{*}$ \\
\hline \multicolumn{7}{|c|}{ Angular measurments $\left(^{\circ}\right)$ : } \\
\hline SNA & 83.00 & 1.51 & 80.00 & 1.25 & 7.356 & $0.0000^{*}$ \\
\hline SNB & 80.14 & 2.25 & 78.71 & 1.57 & 2.5094 & $0.0158^{*}$ \\
\hline SNPg & 82.14 & 1.35 & 79.33 & 1.20 & 7.4277 & $0.0000^{*}$ \\
\hline ANB & 2.95 & 1.33 & 3.08 & 1.28 & -0.3346 & 0.7394 \\
\hline $\mathrm{ML} / \mathrm{SN}$ & 34.91 & 1.34 & 29.92 & 1.21 & 13.2545 & $0.0000^{*}$ \\
\hline $\mathrm{NL} / \mathrm{SN}$ & 9.41 & 1.29 & 9.58 & 0.97 & -0.5179 & 0.6071 \\
\hline $\mathrm{ML} / \mathrm{NL}$ & 23.23 & 1.23 & 22.83 & 1.24 & 1.0799 & 0.2860 \\
\hline
\end{tabular}


Table 2. Craniofacial measurements in males of the study and control groups

\begin{tabular}{|c|c|c|c|c|c|c|}
\hline & \multicolumn{2}{|c|}{ Study group $n=37$} & \multicolumn{2}{|c|}{ Control group $n=40$} & \multirow[b]{2}{*}{$\mathrm{t}$} & \multirow[b]{2}{*}{$\mathrm{p}$} \\
\hline & mean & SD & mean & SD & & \\
\hline Age & 13.25 & 2.64 & 13.67 & 3.14 & 7.1836 & $0.0000^{*}$ \\
\hline \multicolumn{7}{|c|}{ Linear measurements $(\mathrm{mm}):((\mathrm{mm}(\mathrm{mm})[\mathrm{mm}]:$} \\
\hline Cd-Gn & 117.47 & 2.59 & 111.81 & 2.99 & 5.6087 & $0.0000^{*}$ \\
\hline Go-Pg & 73.13 & 2.03 & 71.44 & 2.22 & 2.2144 & $0.0348^{*}$ \\
\hline Cd-A & 90.67 & 3.19 & 88.56 & 2.13 & 2.1691 & $0.0384^{*}$ \\
\hline Pm-A & 48.27 & 3.49 & 47.19 & 2.71 & 0.9639 & 0.3430 \\
\hline S-N & 70.33 & 3.22 & 70.31 & 3.32 & 0.0177 & 0.9859 \\
\hline S-Go & 76.47 & 1.96 & 74.00 & 2.06 & 3.4063 & $0.0019^{*}$ \\
\hline $\mathrm{N}-\mathrm{Me}$ & 112.20 & 2.93 & 111.75 & 2.54 & 0.4573 & 0.6508 \\
\hline Ans-Me & 67.27 & 1.98 & 64.12 & 1.71 & 4.7387 & $0.0000^{*}$ \\
\hline \multicolumn{7}{|c|}{ Angular measurments $\left({ }^{\circ}\right)$ : } \\
\hline SNA & 82.13 & 1.06 & 82.31 & 1.25 & -0.4289 & 0.6711 \\
\hline SNB & 83.26 & 1.03 & 78.31 & 1.35 & 11.4041 & $0.0000^{*}$ \\
\hline SNPg & 82.87 & 1.06 & 79.62 & 0.96 & 8.9454 & $0.0000^{*}$ \\
\hline ANB & 2.47 & 0.91 & 2.75 & 1.00 & -0.8211 & 0.4182 \\
\hline $\mathrm{ML} / \mathrm{SN}$ & 38.60 & 1.12 & 33.62 & 1.54 & 10.2058 & $0.0000^{*}$ \\
\hline $\mathrm{NL} / \mathrm{SN}$ & 10.40 & 0.91 & 10.44 & 1.03 & -0.107 & 0.9154 \\
\hline $\mathrm{ML} / \mathrm{NL}$ & 22.73 & 1.44 & 22.37 & 1.15 & 0.7695 & 0.4478 \\
\hline
\end{tabular}

$\mathrm{SD}$ - standard deviation

${ }^{*} p<0.05$

As far as linear measurements are concerned, the greatest difference was found in mandibular length (Cd-Gn), which was $5.4 \mathrm{~mm}$ greater in females $(\mathrm{p}<0.05)$ and $5.66 \mathrm{~mm}$ in males $(\mathrm{p}<0.05)$, compared to the controls. Corpus length $(\mathrm{Go}-\mathrm{Pg})$ was reported to be $2.67 \mathrm{~mm}$ greater in females $(\mathrm{p}<0.05)$ and $1.69 \mathrm{~mm}$ greater in males $(\mathrm{p}<0.05)$ in comparison to the control group. A significant difference was found in the midfacial length (Cd-A), which was $5.36 \mathrm{~mm}$ greater in females $(\mathrm{p}<0.05)$ and 2.11 greater in males $(\mathrm{p}<0.05)$, compared to the normal-weight individuals. A significant difference in the maxillary length (Pm-A) was found only in females, and was reported to be $1.97 \mathrm{~mm}$ greater than in the controls $(\mathrm{p}<0.05)$. Posterior facial height (S-Go) was significantly greater only in males and was found to be 2.47 greater compared to the normal-weight controls $(\mathrm{p}<0.05)$. A significant difference was observed in the lower anterior facial height (Ans-Me) in both females $(\mathrm{p}<0.05)$ and males $(\mathrm{p}<0.05)$, and was reported to be $2.82 \mathrm{~mm}$ greater in females and $3.15 \mathrm{~mm}$ greater in males. No significant difference was found in the cranial base length ( $\mathrm{S}-\mathrm{N})$ and anterior facial height (N-Me), neither in females nor males of the study group in comparison with the control group.

As regards angular measurements, in the sagittal dimension, females of the study group exhibited significantly greater SNA, SNB and SNPg angles $(\mathrm{p}<0.05)$, indicating a more prognathic position of the jaws compared to the normal-weight individuals. Males of the study group showed significantly greater SNB and SNPg angles $(\mathrm{p}<0.05)$, indicating a more prognathic position of the mandible in comparison with the normal-weight subjects, whereas no significant difference was observed in SNA angle in the males group. In the vertical dimension, a significantly greater ML/
SN angle was found both in females $(\mathrm{p}<0.05)$ and males of the study group $(\mathrm{p}<0.05)$, compared to the controls.

\section{DISCUSSION}

The worldwide pandemic of childhood obesity has generated interest in the relationship between obesity during childhood and adolescence and growth patterns $[10,11,12]$. There is evidence suggesting that before puberty, obese children have a higher height velocity in comparison with their normalweight peers. However, this appears to be followed by a reduction in height gain during puberty. This latter effect, along with the earlier pubertal maturation reported in obese children, leads to similar adult height in obese children compared to the normal-weight peers. Some studies have even reported shorter adult statural height in individuals who had been obese during childhood [17].

Whether or not there is a similar growth pattern in the craniofacial complex of the obese individuals remains an unanswered question. The bones and soft tissues of craniofacial complex appear to grow differently in the obese patients, and the differences between obese and normalweight subjects have just begun to be studied.

The mechanisms that regulate craniofacial growth and development are complex and include interactions between genes, hormones, nutrients and epigenetic factors that give craniofacial bones their final morphology. Disturbance in any of these mechanisms may result in an aberrant growth pattern [21]. There is an evidence that growth hormone $(\mathrm{GH})$ secretion is significantly reduced in obese individuals. Numerous factors seem to be associated with this phenomenon although the exact reason for the reduction as not been fully established. Cephalometric studies in children with GH deficiency demonstrated a smaller anterior and posterior cranial base, small posterior facial height, short ramus height, and smaller maxillary and mandibular length. Patients with GH deficiency have a short anterior cranial base and a relatively large anterior facial height. The maxilla seems to be less affected than the mandible. The mandibular plane angle has been reported to be greater than normal in $\mathrm{GH}$-deficient patients $[20,21,22]$.

These findings suggest that factors other than GH level are responsible for increased craniofacial dimensions observed in obese adolescents. Hyperinsulinaemia and a high level of IGF-1 may be growth stimulating factors. The theory that craniofacial growth may be more dependent on free circulating IGF-1 rather than on the level of GH seems to be attractive in this context.

Despite the decreased level of GH observed in overweight and obese individuals, the findings of the current study showed greater craniofacial dimensions in adolescents with high BMI percentile compared to the normal-weight peers. The results of the study are in line with previous research. In the study of Sadeghianrizi et al., both obese adolescent males and females showed significantly greater mandibular and maxillary dimensions than the controls. Mandibular length (Cd-Pgn) was $9.7 \mathrm{~mm}$ greater in obese males and 7.5 greater in obese females, compared to the normal-weight individuals. Corpus length (Go-Pg) was $3 \mathrm{~mm}$ longer in obese adolescents than in the controls. Maxillary length (Pm-A) was $3.5 \mathrm{~mm}$ greater in obese males and $3.0 \mathrm{~mm}$ greater in obese females in comparison with the normal-weight subjects. In the vertical 
dimension, lower anterior facial height (Ans-Gn) was $4 \mathrm{~mm}$ greater in males and $3.8 \mathrm{~mm}$ greater in females, whereas posterior facial height (S-Go) was $4.9 \mathrm{~mm}$ greater in males and $4 \mathrm{~mm}$ greater in females [23]. In the study by Öhrn et al., several linear and angular measurements were increased in obese adolescents compared to the healthy controls. The largest difference was found in the length of the mandible (Cd-Pgn), which was 8.7 greater in males and 6.0 greater in females compared to the normal-weight controls. Obese adolescents showed increased mandibular and maxillary prognathism, as well as an elongated anterior cranial base (S-Na), compared to the controls [24].

In dentofacial orthopaedics, control of craniofacial growth is essential for determining correct treatment timing, selection of treatment methods, as well as for predicting stability during the retention period. It is widely known that antero-posterior growth patterns of craniofacial structures are particularly important during adolescence when children undergo a growth spurt. Growth spurt has been reported for maxillary length and for overall mandibular length, corpus length and ramus height. Peak growth velocities occurr $0.7-1.35$ years earlier for the maxillary than mandibular measurements, and are strongly correlated with the timing of statural growth spurt [26]. Taking into account that growth patterns are different in overweight or obese individuals compared to normal-weight peers, when incorporating orthopaedic therapy such as growth modification, the timing of intervention may require recalculation to consider not only gender, but also the weight status of the patient.

\section{CONCLUSIONS}

The study revealed significantly greater craniofacial measurements in overweight and obese orthodontic adolescent patients, compared with normal-weight controls.

Weight status is an important factor that can affect craniofacial growth pattern and should be taken into consideration when planning orthopaedic treatment in adolescent patients.

\section{REFERENCES}

1. Ng M, Fleming T, Robinson M. Global, regional and national prevalence of overweight and obesity in children and adults during 1980-2013: a systematic analysis for the Global Burden of Disease Study 2013. Lancet 2014; 384 (9945): 766-781.

2. World Health Organization: Prioritizing areas for action in the field of population-based prevention of childhood obesity. WHO, Geneva 2102.
3.Żukiewicz-Sobczak W, Wróblewska P, Zwoliński J, ChmielewskaBadora J, Adamczuk P, Krasowska E, Zagórski J, Oniszczuk, A, Piątek J, Silny W. Obesity and poverty paradox in developed countries. Ann Agric Environ Med 2014; 21(3): 590-594.

4. Bac A, Woźniacka R, Matusik S, Golec J, Golec E. Prevalence of overweight and obesity in children aged 6-13 years - alarming increase in obesity in Cracow, Poland. Eur J Pediatr 2012; 171: 245-251.

5. Mazur A, Klimek K, Telega G, Filip R, Małecka-Tendera E. Ten-year secular trend of overweight and obesity in school children in SouthEastern Poland. Ann Agric Environ Med 2014; 21(3): 634-638.

6. Kuczmarski RJ, Ogden CL, Guo SS, Grummer-Strawn LM, Flegal KM, Mei Z: 2000 CDC growth charts for the United States: methods and development. Vital Health Stat 2002; 246: 1-190.

7. Cole TJ, Lobstein T. Extended internationl (IOTF) body mass index cutoffs for thinnes, overweight and obesity. Pediatr Obes 2012; 7: 284-294.

8. Neeley WW, Gonzales DA. Obesity in adolescence: Implications in orthodontic treatment. Am J Orthod Dentofacial Orthop 2007; 131: 581-8.

9. Giuca MR, Pasini M, Tecco S, Marchetti E, Giannotti E, Marzo G. Skeletal maturation in obese patients. Am J Orthod Dentofacial Orthop 2012; 142: 774-9.

10. Sandhu J, Ben-Shlomo Y, Cole TJ, Holly J, Smith GD. The impact of childhood body mass index on timing of puberty, adult stature and obesity: a follow-up study based on adolescent anthropometry recorded at Christ's Hospital. Int J Obesity 2006; 30: 14-22.

11. Ahmed ML, Ong KK, Dunger DB. Childhood obesity and the timing of puberty. Trends Endocrin Met 2009; 20(5): 237-242.

12. Dunger DB, Ahmed ML, Ong KK. Effects of obesity on growth and puberty. Best Pract Res Clin Endocrinol Metab 2005; 19(3): 375-390.

13. Bradner Jasik C, Lustig LH. Adolescent obesity and puberty: the perfect storm. Ann NY Acad Sci 2008; 1135: 265-279.

14. Mack K, Philips C, Jain N, Koroluk LD. Relationship between body mass index percentile and skeletal maturation and dental development in orthodontic patients. Am J Orthod Dentofac Orthop 2013; 143: 228-234.

15. Kaplowitz PB. Link between body fat and the timing of puberty. Pediatrics 2008; 121(Suppl. 3): S208-S217.

16. Hilgers KK, Akridge M, Scheetz JP, Kinane DF. Childhood obesity and dental development. Pediatr Dent 2006; 28: 18-22.

17. De Leonibus C, Marcovecchio ML, Chiavaroli V, de Giorgis T, Chiarelli F. Timing of puberty and physical growth in obese children: a longitudinal study in boys and girls. Pediatr Obes 2013; 9: 292-299.

18. Zhang Y, Proenca R, Maffei M. Positional cloning of the mouse obese gene and its human homologue. Nature 1994; 372: 425-432.

19. Yagasaki Y, Yamaguchi T, Watahiki J, Konishi M, Katoh H, Maki K. The role of craniofacial growth in leptin deficient mice. Orthod Craniofacial Res 2003; 6: 233-241.

20. Oliveira-Neto LA, Melo Mde F, Franco AA. Cephalometric features in isolated growth hormone deficiency. Angle Orthod 2011; 81: 578-583.

21. Litsas G. Growth hormone therapy and craniofacial bones: a comprehensive review. Oral Diseases 2013; 19: 559-567.

22. Partyka M, Dunin-Wilczyńska I, Chałas R. Zaburzenia układu stomatognatycznego u osób z niskorosłością. Pol Med J 2014; 211: 63-67.

23. Öhrn K, Al-Kahlili B, Huggare J, Forsberg CM, Marcus C. Craniofacial morphology in obese adolescents. Acta Odontol Scand 2002; 60: 193-197.

24. Sadeghianrizi A, Forsberg CM, Marcus C, Dahllöf G. Craniofacial development in obese adolescents. Eur J Orthod 2005; 27: 550-555.

25. Ferrario V, Dellavia C, Tartaglia G, Turci M, Sforza C. Soft tissue facial morphology in obese adolescents: a three dimensional non-invasive assessment. Angle Orthod 2004; 74: 37-42.

26. Buschang PH, Jacob HB, Demirjian A. Female adolescent craniofacial growth spurts: real or fiction? Eur J Orthod 2013; 35: 819-825. 